\title{
An Experimental Study on The Influence of Nano Silica on the Strength and Durability Characteristics of Self Compacting Concrete
}

\author{
K. Satish Kumar Reddy ${ }^{1}$, D. Mohammed Rafi², A.B.S. Dadapeer ${ }^{3}$ \\ ${ }^{* 1}$ M.Tech Student, St.Mark Eucational Institution Society Group of Institutions, Anantapur, Andhra Pradesh, India \\ 2 \& *3Assistant Professor, St.Mark Eucational Institution Society Group of Institutions, Anantapur, Andhra Pradesh, \\ India
}

\begin{abstract}
Article Info
Volume 7, Issue 5

Page Number: 295-302

Publication Issue :
\end{abstract}

September-October-2020

\section{Article History}

Accepted : 15 Oct 2020

Published : 20 Oct 2020

\section{ABSTRACT}

Self-compacting concrete (SCC) is also considered as a concrete which can be placed and compacted under its own weight with little or no vibration without segregation or bleeding. The use of SCC with its improving productions techniques is increasing everyday in concrete production. It is used to facilitate and ensure proper filling and good structural performance of heavily reinforced structural members. Recently, nano particles have been gaining increasing attention and have been applied in many fields to fabricate new materials with novel functions due to their unique physical and chemical properties. Degradation of concrete members exposed to aggressive sulphuric acid environments is a key durability issue that affects the life cycle performance and maintenance costs of vital civil infrastructure. Sulphuric acid in groundwater, chemical waste or generated from the oxidation of sulphur bearing compounds in backfill can attack substructure concrete members. Moreover, concrete structures in industrial zones are susceptible to deterioration due to acid rain of which sulphuric acid is a chief component.

In this work $40 \mathrm{Mpa}$ self-compacting concrete is developed using modified Nan-Su method of mix design. Slump flow, J-Ring, V-funnel tests are conducted to justify the fresh properties of SCC and are checked against EFNARC (2005) specifications. Specimens of dimensions 150x150x150mm were cast without nano silica and with two nano silica are added in different percentages $(1 \%, 1.5 \%$ and $2 \%$ by weight of cement) to SCC. To justify the compressive strength for 7 and 28days, specimens are tested under axial compression. Durability properties were also studied by immersing the specimensin $5 \% \mathrm{HCl}$ and $5 \% \mathrm{H}_{2} \mathrm{SO}_{4}$. The particle packing in concrete can be improved by using Nano-silica which leads to densifying of the micro and nanostructure resulting in improved mechanical properties. Nano-silica addition to cement based materials can also control the degradation of the fundamental C-S-H (calcium-silicate-hydrate) reaction of concrete caused by calcium leaching in water as well as block water penetration and therefore lead to improvements in durability.

Keywords : Bleeding, Compaction, Deterioration, Durability, Nano Silica, Nanostructure, Segregation, Penetration

Copyright: (C) the author(s), publisher and licensee Technoscience Academy. This is an open-access article distributed under the terms of the Creative Commons Attribution Non-Commercial License, which permits unrestricted noncommercial use, distribution, and reproduction in any medium, provided the original work is properly cited 


\section{INTRODUCTION}

Self-Compacting Concrete (SCC) is a new generation of concrete, which has generated tremendous interest since its initial development in Japan by Okamura in the late 1980's in order to reach durable concrete structures. SCC has gained wide use for placement in congested reinforced concrete structures with difficult casting conditions. For such applications, the fresh concrete must possess high fluidity and good cohesiveness. SCC is considered as a concrete which can be placed and compacted under its self-weight with little or no vibration effort, and which is at the same time, cohesive enough to be handled without segregation or bleeding. It is used to facilitate and ensure proper filling and good structural performance of heavily reinforced structural members. SCC development is a desirable achievement in the construction industry in order to overcome problems associated with cast-in-place concrete. SCC is not affected by the skills of workers, the shape and amount of reinforcing bars or the arrangement of a structure and, due to its high-fluidity and resistance to segregation it can be pumped longer distances. The main advantage of SCC is to shorten construction period and to assure compaction in the structures especially in the confined zones where vibration and compaction is difficult. The other advantages of SCC are

1. It eliminates noise due to vibration.

2. It provides high stability during transport and placement.

3. It provides uniform surface quality and homogenous.

4. It provides greater freedom for design

5. It is useful for casting of underwater structures.

The concept of SCC was proposed in 1986 by Professor Hajime Okamura, but the prototype was first developed in 1988 in Japan, by Professor Ozawa at the University of Tokyo. SCC was developed at that time to improve the durability of concrete structures. Since then, various investigations have been carried out and SCC has been used in practical structures in Japan, mainly by large construction companies. Investigations for establishing a rational mix design method and Self-Compactability, testing methods have been carried out from the viewpoint of making it a standard concrete. SCC is cast so that no additional inner or outer vibration is necessary for the compaction. It flows like "honey" and has a very smooth surface level after placing. With regard to its composition, SCC consists of the same components as Conventional concrete, which are cement, aggregates, and water, with the addition of chemical and mineral admixtures in different proportions. Usually, these concretes have higher workability, superior mechanical properties and/or greater resistance to chemical attack as compared to traditional concrete.

\section{Development of Self-Compacting Concrete}

The main motive for development of SCC was the social problem on durability of concrete structures that arose around 1983 in Japan. Due to a gradual reduction in the number of skilled workers in Japan's construction industry, a similar reduction in the quality of construction work took place. As a result of this fact, one solution for the achievement of durable concrete structures independent of the quality of construction work was the employment of SCC, which could be compacted into every corner of a formwork, purely by means of its own weight. Studies to develop SCC, including a fundamental study on the workability of concrete, were carried out by researchers Ozawa and Maekawa at the University of Tokyo. 


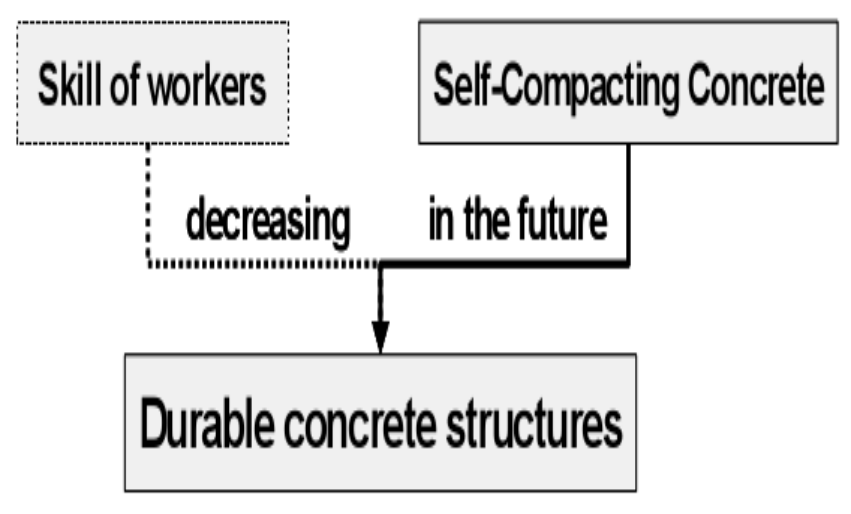

II. LITERATURE REVIEW

\section{Self-compacting Concrete}

From the foregoing discussion, it is clear that the main aim of the work is developing a SCC and understands the behaviour of such a SCC under various loading action. In the early 1990's there was only a limited public knowledge about the use of selfcompacting concrete, and if available that was mainly in Japanese. The first paper on self compaction concrete was presented by Ozawa at the second EastAsia and pacific conference on structural engineering and construction in January 1989.

\section{Previous Research Work on Self-Compacting Concrete:}

Self-compacting concrete extends the possibility of use of various mineral by-products in its manufacturing and with the densification of the matrix, mechanical behaviour, as measured by compressive, tensile and shear strength, is increased. On the other hand, the use of super plasticizers or high range water reducers, improves the stiffening, unwanted air entrainment, and flowing ability of the concrete. Practically, all types of structural constructions are possible with this concrete. The use of SCC not only shortens the construction period but also ensures quality and durability of concrete. This non-vibrated concrete allows faster placement and less finishing time, leading to improved productivity. In the following paragraph, a summary of the articles and papers found in the literature, about the selfcompacting concrete and some of the research work carried out with this type of concrete, are presented.

Hajime okamura [1]:A new type of concrete, which can be compacted into every corner of a formwork purely by means of its own weight, was proposed by Okamura in 1986, he started a research project on the flowing ability and workability of this special type of concrete, later called self-compacting concrete. The Self-Compactability of this concrete can be largely affected by the characteristics of materials and the mix proportions. In his study, Okamura (1997) has fixed the coarse aggregate content to $50 \%$ of the solid volume and the fine aggregate content to $40 \%$ of the mortar volume, so that self compactability could be achieved easily by adjusting the water to cement ratio and superplasticizer dosage only.

Kazumasa ozawa (1988)[2] he succeeded in developing SCC for the first time. The year after that, an open experiment on the new type of concrete was held at the University of Tokyo, in front of more than 100researchers and engineers. As a result, intensive research has begun in many places, especially in the research institutes of large construction companies and the University of Tokyo.

Domone et al (1999)[3] has done their research on the effect on fresh properties of mortar phase of SCC of four different types of superplasticizer and various combinations of powder, including Portland cement, GGBS, fly ash, micro silica and lime stone powder. He concluded that many of important parameters that influence the performance SCC can be assessed by testing on mortars. This include the comparison of the performance of different super plasticizer of the effects of the time of addition of the super plasticizer during mixing process and the work ability and workability retention characteristics of mixes containing binary and ternary blends of powders. 
Nan su et al [4], proposed a simple mix design method for SCC. The amount of aggregates required is determined, and the paste of binders is then filled into the voids of aggregates to ensure that the concrete thus obtained has flow ability, selfcompacting ability and other desired SCC properties. The amount of aggregates, binder, and mixing water, as well as type and dosage of super plasticizer (SP) to be used are the major factors influencing the properties of SCC. Slump flow, V-funnel, L-flow, Ubox and compressive strength tests were carried out to examine the performance of SCC, and the results indicate that the proposed method could produce successfully SCC of high quality.

\section{MECHANISM FOR ACHIEVING SCC}

The method for achieving SCC involves not only high deformability of paste or mortar, but also resistance to segregation between coarse aggregate and mortar when concrete flows through the confined zones of reinforcing bars.

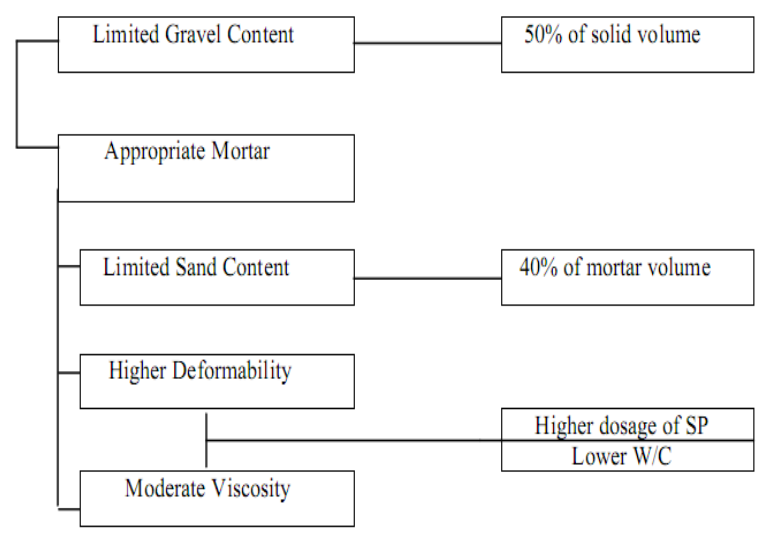

Fig: Methods for achieving self-compactability

The frequency of collision and contact between aggregate particles can increase as the relative distance between the particles decreases and then internal stress can increase when concrete is deformed, particularly near obstacles. Research has found that the energy required for flowing is consumed by the increased internal stress, resulting in blockage of aggregate particles limiting the coarse aggregate content, whose energy consumption is particularly intense, to a level lower than normal is effective in avoiding this kind of blockage.

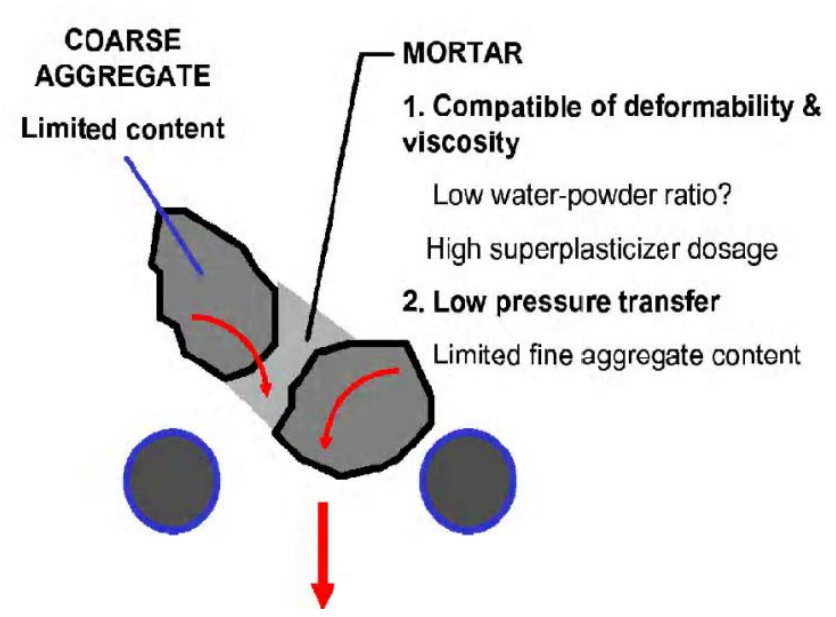

Fig: Mechanism for achieving self-compactability

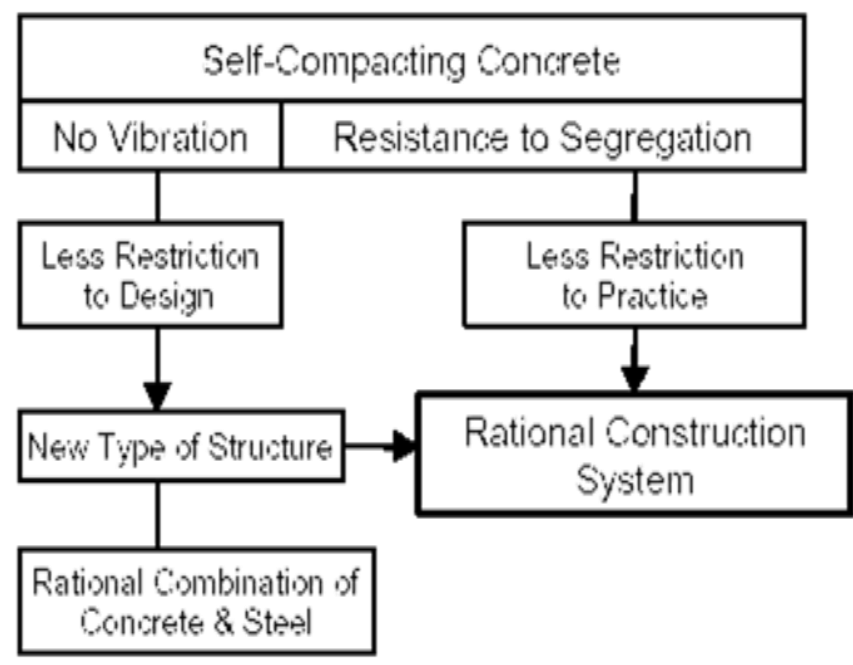

Fig: Rational construction system proposed by Ozawa

\section{Composition of SCC}

SCC is a fluid mixture, which is suitable for placing in difficult conditions and in structures with congested reinforcement, without vibration. In principle, a self-compacting or self-consolidating concrete must: 
- Have a fluidity that allows self-compaction without external energy,

- Remain homogeneous in a form during and after the placing process, and

- Flow easily through reinforcement.

The technology of SCC is based on adding or partially replacing Portland cement with amounts of fine material such as fly ash, blast furnace slag, and silica fume without modifying the water content compared to common concrete. This process changes the rheological behavior of the concrete.

\section{NANO TECHNOLOGY}

\section{"Nanotechnology is the art and science of} manipulating matter at the nano scale". Nanotechnology is the creation of materials and devices by controlling of matter at the levels of atoms, molecules, and supramolecular (nanoscale) structures. In other words, it is the use of very small particles of materials to create new large scale materials.

\section{Nano materials}

The Nano materials can improve vital characteristics of construction materials such as strength, durability, and lightness, endow useful properties (e.g., heatinsulating, self-cleaning, and antifogging), and function as key sensing components to monitor construction safety and structural health. The particle packing in concrete can be improved by using Nanosilica which leads to densifying of the micro and nanostructure resulting in improved mechanical properties. Nano-silica addition to cement based materials can also control the degradation of the fundamental C-S-H (calcium-silicate-hydrate) reaction of concrete caused by calcium leaching in water as well as block water penetration and therefore lead to improvements in durability. Carbon nanotubes (CNTs) when used as a proxy for polymeric chemical admixtures can remarkably improve mechanical durability by gluing concrete mixtures, that is, cementitious agents and concrete aggregates, and prevent crack propagation. Incorporation of CNTs as crack bridging agents into non-decorative ceramics can enhance their mechanical strength and reduce their fragility, as well as improve their thermal properties.

$\mathrm{SiO}_{2}$ and $\mathrm{Fe}_{2} \mathrm{O}_{3}$ nanoparticles (NPs) can be used as filling agents to pack the pores and reinforce concrete to prevent the penetration of $\mathrm{CaCl}_{2}$ and $\mathrm{MgCl}_{2}$ into nano- or micropores that concrete develops due to cement hydration, reacting with concrete constituents to weaken the structure.

Addition of magnetic nickel nano-particles during concrete formation increases the compressive strength by over $15 \%$ as the magnetic interaction enhances the mechanical properties of cement mortars.

Copper nano-particles mitigate the surface roughness of steel to promote the weld ability and render the steel surface corrosion-resistant.

One of the principal structural units in nanotechnology is quantum dot or nanoparticle, which can be represented as a cluster of tens to thousands of atoms of 1-100 nm in diameter. The key is the size of particles because the properties of materials are dramatically affected under a scale of the nanometer (nm), 10-9 meter (m).

\section{Nano-Silica (Nano-Sio2)}

Nano-Silica(NS) is the first nano product that replaced the micro silica. It has a specific surface area near to $1,00,000 \mathrm{~m}^{2} / \mathrm{kg}$ (micro silica has only 20,000 $\mathrm{m}^{2} / \mathrm{kg}$ ) and a particle size of $5 \mathrm{~nm}$ to $250 \mathrm{~nm}$. Nano Silica (NS) can contribute to efficient 'Particle Packing' in concretes by densifying the micro and nanostructure leading to improved mechanical and durability properties.

NS can control degradation (through blocking of water entry on account of pore refinement) of the 
fundamental binder system of hydrated cement i.e., C-S-H gel caused usually due to calcium leaching out when immersed in water. NS improves behaviour of freshly mixed cement concretes by imparting segregation resistance and by enhancing both workability and cohesion of the matrix.

\section{Durability Aspects of SCC}

The durability of cement concrete is defined as the ability to resist weathering action, chemical attack, abrasion, or any other process of deterioration. Although SCC is a very promising cementitious material, the actual application of SCC might be somewhat riskful due to lack of knowledge concerning its actual durability. The degradation mechanisms of cementitious material are greatly influenced by the permeability of the material for potentially aggressive media and there is an important interaction between 'pore structure', 'transport mechanism' and 'degradation'. The permeability itself is strongly influenced by the pore structure of the material. Furthermore the ongoing degradation process might have an influence on the pore structure of the material. As the pore structures might be different for SCC in comparison with traditional concrete, due to difference in the composition, some changes in durability behaviour might occur.

\section{EXPERIMENTAL INVESTIGATION}

\section{Introduction of Experimental Study}

The experimental study consists of arriving at suitable mix proportions that satisfied the fresh properties of self-compacting concrete as per EFNARC specifications. Standard cube moulds of $150 \mathrm{~mm} \mathrm{x}$ $150 \mathrm{~mm} \times 150 \mathrm{~mm}$ made of cast iron were used for casting standard cubes. The standard moulds were fitted such that there are no gaps between the plates of the moulds. If there are any small gaps they were filled with plaster of paris. The moulds were then oiled and kept ready for casting. After 24hrs of casting, specimens were demoulded and transferred to curing tank where in they were immersed in water for the desired period of curing.

The program consists of casting and testing of 40Mpa Self-compacting Concrete with additions of nano silica and without nano silica. A total of 7batches were made, out of which 1batch is of normal SCC i.e.,without nano silica, 3batches of nano silica( $16 \%$ nano content) with additions of $1 \%, 1.5 \%$ and $2 \%$ bwoc and 3batches of nano silica(30\% nano content) with additions of $1 \%, 1.5 \%$ and $2 \%$ bwoc. The mix proportion for $40 \mathrm{Mpa}$ Self-compacting concrete was designed by using modified nan su method. Water reducing admixtures are added into mixes on requirement, till the desired properties are exhibited by them. 15cubes were casted in each batch, out of which 6cubes of each batch are tested for compressive strength for 7days and 28days, 3cubes of each batch are tested for $5 \% \mathrm{H}_{2} \mathrm{SO}_{4}$ (sulphuric acid), $5 \% \mathrm{HCl}$ ( Hydrochloric acid) and Sorptivity test for durability aspects.

\section{Compressive Strength}

The cube specimens were tested on compression testing machine of capacity $2000 \mathrm{kN}$. The bearing surface of the machine was wiped off clean and any loose sand or other material removed from the surface of the specimen .The specimen was placed in the machine in such a manner that the load was applied to opposite sides of the cubes as caste that is, not top and bottom. The axis of the specimen was carefully aligned at the center of the loading frame. The load applied was increased continuously at a constant rate until the resistance of the specimen to the increasing load breaks down and no longer can be sustained. The maximum load applied on the specimen was recorded. The details of compressive strength results for specimens without and with nano silica were compared. 


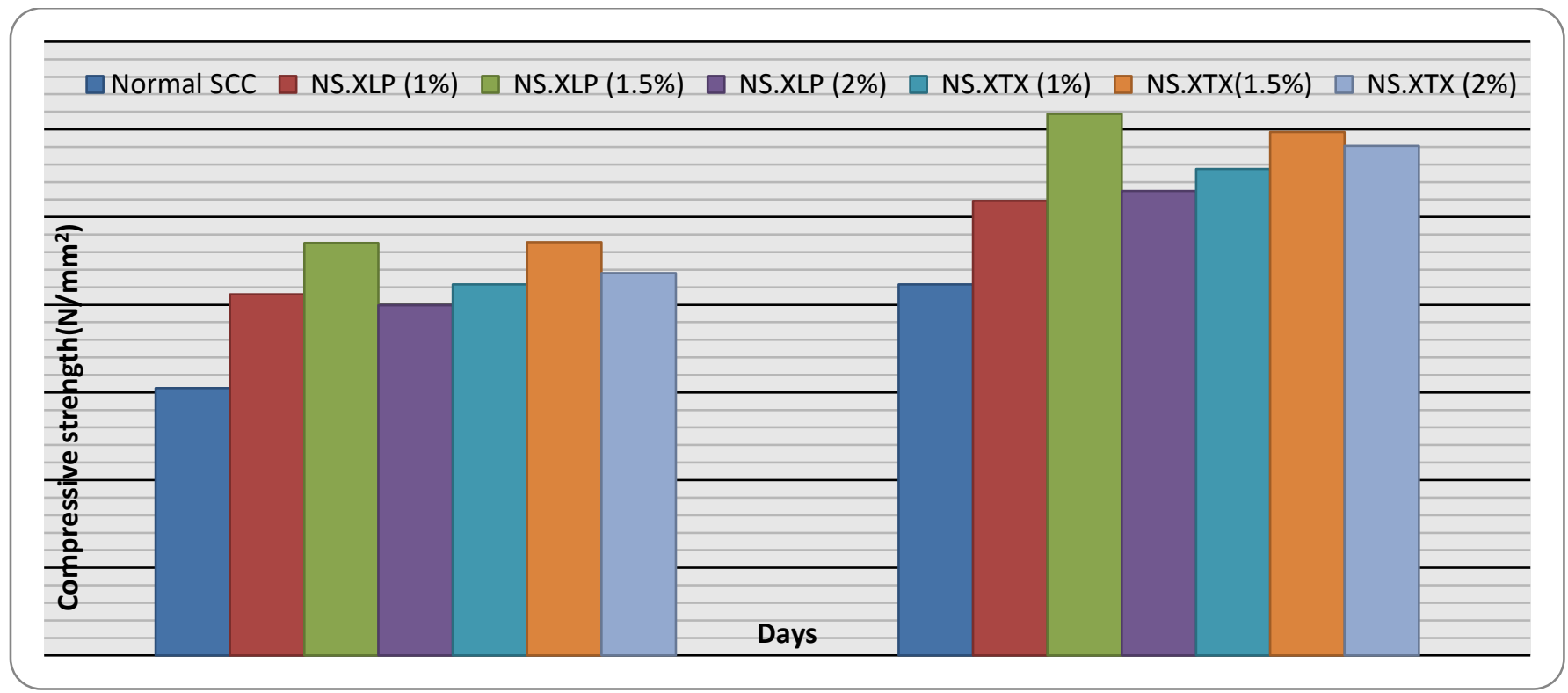

Fig 1 : Average compressive strength of SCC without and with nano silica

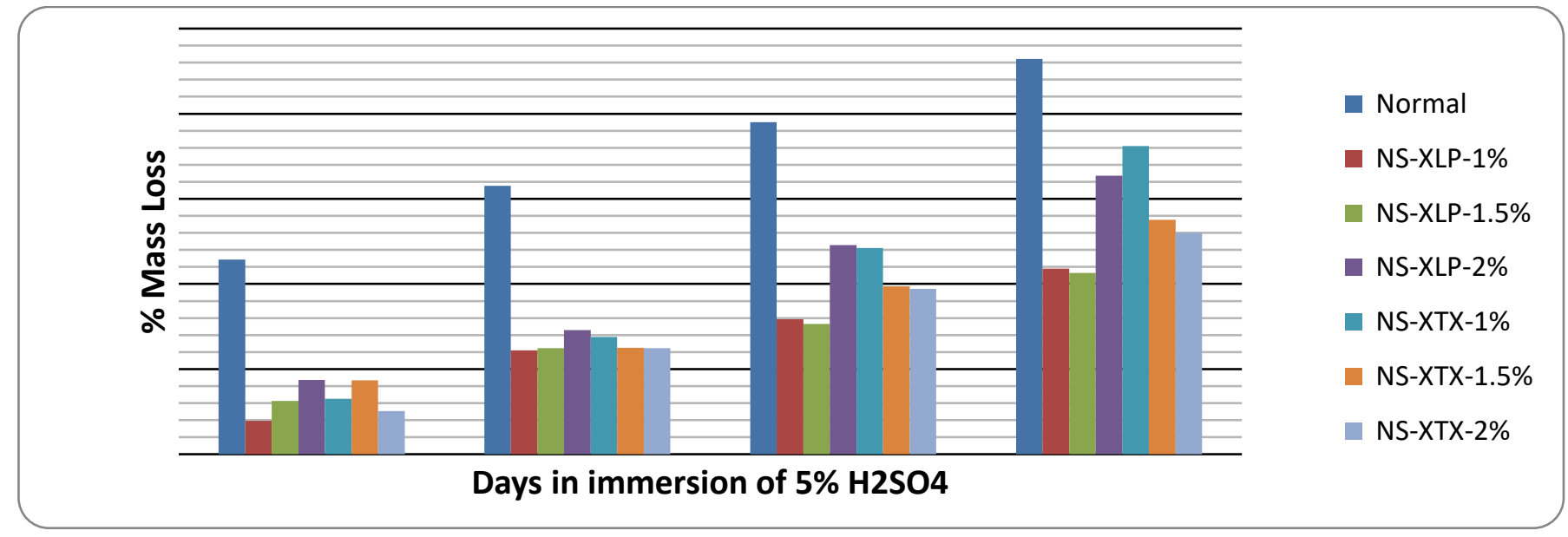

Fig 2 : Percentage mass losses when immersed in 5\% Sulphuric acid solution

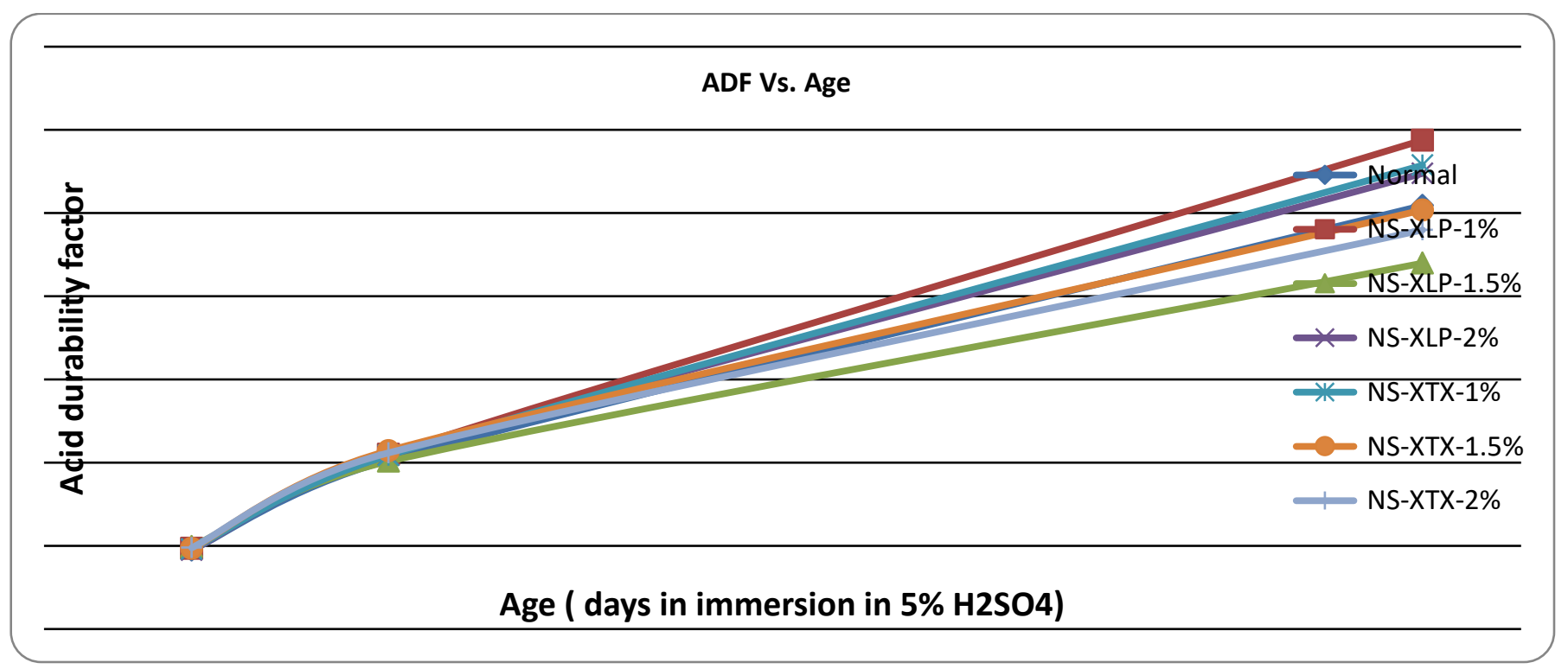

Fig 3 : Graph between Acid Durability Factor and No. of days in immersion in 5\% $\mathrm{H}_{2} \mathrm{SO}_{4}$ 


\section{CONCLUSION}

The present work deals with understanding the effect of nano silica inclusion on strength and durability properties of self-compacting concrete.

\section{Effect of Nano Silica on Compressive Strength:}

1. In the present study $40 \mathrm{Mpa}$ SCC was developed based on modified nan su method and nano silica additions are made in that.

2. There is a steep increase in the compressive strength at 28days of about $45.2 \%$ and $41.13 \%$ with the addition of $1.5 \%$ Nano silica of XLP grade and XTX grade respectively. Hence $1.5 \%$ addition of nano silica is said to optimum.

3. The addition of nano silica improves the hydrated structure of concrete.

\section{Effect of Nano Silica on Durability:}

1. The surface of the specimens was badly damaged and cement mortar was completely eaten up in $5 \% \mathrm{H}_{2} \mathrm{SO}_{4}$ and it was not found in $5 \% \mathrm{HCl}$.

2. The percentage mass loss with $5 \% \mathrm{H}_{2} \mathrm{SO}_{4}$ and $5 \%$ $\mathrm{HCl}$ revealed that nano additions have less percentage of mass loss than normal SCC.

3. After 28 days, the percentage mass loss for Nano Silica XLP with $1.5 \%$ addition is $1.06 \%$ in $5 \%$ sulphuric acid, which is said to less when compared to other percentage of nano silica.

4. After 28 days, the percentage mass loss for Nano Silica XTX with $2 \%$ addition is $1.81 \%$ in $5 \%$ hydrochloric acid, which is said to less when compared to other percentage of nano silica.

5. The percentage loss of both compressive strength and weight are increasing with the time of exposure to acid attack.

The percentage compressive strength loss is more for 1.5\% Nano Silica-XLP and is about $56.02 \%$ and $18.74 \%$ with $5 \% \mathrm{H}_{2} \mathrm{SO}_{4}$ and $5 \% \mathrm{HCl}$ respectively after 28 days of immersion. This may be due to higher pozzalonic content.

\section{REFERENCES}

[1]. Hajime Okamura and Masahiro Ouchi (2003), "Self-Compacting Concrete", Journal of Advanced Concrete Technology Vol.1, No.1, 515, April 2003.

[2]. Ozawa K., Kunishima, M., Maekawa, K. and Ozawa, K, "Development of High Performance Concrete Based on the Durability Design of Concrete Structures". Proceedings of the second East-Asia and Pacific Conference on Structural Engineering and Construction (EASEC-2), Vol. 1, pp. 445-450, January 1989.

[3]. "Specifications and guidelines for selfcompacting concrete." published by EFNARC in February 2005.

[4]. Nan Su, Kung-Chung Hsu, His-Wen Chai, "A simple mix design method for self-compacting concrete", Cement and Concrete Research, 6 June 2001, pp1799-1807.

[5]. S. Venkateswara Rao, M.V. Seshagiri Rao, P. Rathish Kumar "Effect of Size of Aggregate and Fines on Standard And High Strength Self compacting Concrete", Journal of Applied Sciences Research, 6(5): 433-442, 2010.

[6]. M.R.Arefi, M.R. Jahaveri, E. Mollaahmadi,(2011) Silica nanoparticle size effect on mechanical properties and microstructure of cement motar, Journal of American science.

[7]. A.A. Magsoudi, M.Magsoudi, and M. Noori, "Effect of Nanoparticles on SCC", second international conference on sustainable construction materials and technologies.June 28, 2010.

Cite this article as : K. Satish Kumar Reddy, D. Mohammed Rafi, A.B.S. Dadapeer, "An Experimental Study on The Influence of Nano Silica on the Strength and Durability Characteristics of Self Compacting Concrete", International Journal of Scientific Research in Science and Technology (IJSRST), Online ISSN : 2395-602X, Print ISSN : 2395-6011, Volume 7 Issue 5, pp. 295-302, September-October 2020. Available at doi : https://doi.org/10.32628/IJSRST207559 Journal URL : http://ijsrst.com/IJSRST207559 
K. Satish Kumar Reddy et al Int J Sci Res Sci \& Technol. September-October-2020; 7 (5) : 295-302 